\title{
REMOTE SENSING-BASED DETECTION AND SPATIAL PATTERN ANALYSIS FOR GEO-ECOLOGICAL NICHE MODELING OF TILLANDSIA SPP. IN THE ATACAMA, CHILE
}

\author{
N. Wolf ${ }^{\text {a, *, A. Siegmund }}{ }^{\text {a, b }}$, C. del Río ${ }^{c}$, P. Osses ${ }^{\text {c }}$, J. L. García ${ }^{\text {c, d }}$ \\ ${ }^{a}$ Dept. of Geography, Heidelberg University of Education, Germany - (nils.wolf, siegmund)@ ph-heidelberg.de \\ ${ }^{\mathrm{b}}$ Heidelberg Center for the Environment (HCE), Heidelberg University, Germany \\ ${ }^{\mathrm{c}}$ Dept. of Geography, Pontificia Universidad Católica de Chile - (cdelriol, posses, jgarciab)@uc.cl \\ d Atacama Desert Center, Pontificia Universidad Católica de Chile
}

Commission II, WG II/3

KEY WORDS: WorldView-3, fog ecosystems, spatio-spectral classification, geo-ecological modelling

\begin{abstract}
:
In the coastal Atacama Desert in Northern Chile plant growth is constrained to so-called 'fog oases' dominated by monospecific stands of the genus Tillandsia. Adapted to the hyperarid environmental conditions, these plants specialize on the foliar uptake of fog as main water and nutrient source. It is this characteristic that leads to distinctive macro- and micro-scale distribution patterns, reflecting complex geo-ecological gradients, mainly affected by the spatiotemporal occurrence of coastal fog respectively the South Pacific Stratocumulus clouds reaching inlands. The current work employs remote sensing, machine learning and spatial pattern/GIS analysis techniques to acquire detailed information on the presence and state of Tillandsia spp. in the Tarapacá region as a base to better understand the bioclimatic and topographic constraints determining the distribution patterns of Tillandsia spp. Spatial and spectral predictors extracted from WorldView-3 satellite data are used to map present Tillandsia vegetation in the Tarapaca region. Regression models on Vegetation Cover Fraction (VCF) are generated combining satellite-based as well as topographic variables and using aggregated high spatial resolution information on vegetation cover derived from UAV flight campaigns as a reference. The results are a first step towards mapping and modelling the topographic as well as bioclimatic factors explaining the spatial distribution patterns of Tillandsia fog oases in the Atacama, Chile.
\end{abstract}

\section{INTRODUCTION}

The hyperarid coastal zone of northern Chile is home to unique ecosystems which depend on coastal fog as main source of water. Being the remnants of a continuous vegetation belt during the Pliocene, they nowadays occur in disjoint patches, so-called fog oases.

The plant organisms existing under these environmental conditions have developed highly specialized adaptation strategies concerning the availability of water. One of the most characteristic vegetation units from Arica (18 20' S) to the Loa river $\left(21^{\circ} 25^{\prime} \mathrm{S}\right)$ are Tillandsia spp. (Rundel et al., 1997). Tillandsia spp. grow without functional roots and are the ecological dominants over extensive areas of specialized communities called "Tillandsiales" or "Tillandsia lomas" (Westbeld et al., 2009). As Tillandsia spp. depend on fog as primary water and nutrient source, their spatial distribution is constrained to areas covered by coastal fog of sufficient frequency, duration and intensity (Hesse 2012).

The fog water is supplied by regional-scale stratocumulus clouds that develop at the eastern tropical and subtropical southern Pacific Ocean as a result of high evaporation rates in the Pacific Ocean and quasi-permanent regional thermal inversion. At the South American coast, the stratocumulus clouds become an advection fog responsible for the existence of the coastal ecosystems. Because of their influence on the regional and local climate, their ecological effect on coastal plant communities and their potential as a water resource (fog collection/harvesting), these cloud banks, locally known as "camanchaca", have become an important research focus during the last decades (Cereceda et al., 2002; Rutllant 2003; Pinto et al., 2006; Schulz et al., 2012). In this context, several authors constitute the particular sensitivity of Tillandsia spp. to changing environmental conditions at different spatial and time scales and highlight their potential value as bioindicator of climate change

(Rundel et al., 1997; Latorre et al., 2011; Schulz et al., 2011). In fact, in the recent decades the Chilean fog ecosystems have shown increasing signs of decline, which might be linked to abrupt mesoscale climate shifts since the mid-1970s (Schulz et al., 2011). However, the magnitude of the decline and the underlying causal biosphere-atmosphere relationships are yet to be investigated to enable the implementation of more effective conservation strategies. Main gaps exist regarding the explicit linkages between the spatiotemporal variability of the fog clouds and associated fog ecosystems (Hesse 2012) as data requirements remain concerning the spatial distribution patterns of Tillandsia lomas and respective topographic/climatic controls.

Previous studies presenting an area-wide inventory of Tillandsia spp. stands in the Atacama were based on visual interpretation of scanned black-and-white aerial photography in the scale of 1:70,000 (Pinto et al., 2006), which only provide a suboptimal basis for acquiring detailed information on the

\footnotetext{
* Corresponding author
} 
presence, status and formation patterns of the Tillandsia spp. stands (Schulz 2009). In this context, the new generation of high spatial resolution $(<1 \mathrm{~m})$ multispectral commercial earth observation satellites (e.g. QuickBird, IKONOS, WorldView$2 / 3$, Pleiades) has great potential to acquire more detailed and frequent information on their status and change. However, to date automated mapping routines allowing the reproducible, area-wide and cost-efficient generation of data on the presence, formation patterns and change of Tillandsia spp. is missing (Hesse 2012).

At a local/stand level, Tillandsia spp. lomas are known to form distinct spatial patterns which provide indication on the local fog-water inputs and their relation to vegetation density and vitality (Borthagaray et al., 2010). Unmanned aerial vehicles (UAV) are an emerging technology which enables the acquisition of remote sensing imagery in the centimeter range. These images can be processed to detailed elevation models and orthoimage mosaics to deduce local location factors (e.g. orographic obstacles or fog-shadows, slope and aspect) explaining the presence, density and formations of Tillandsia spp. and providing a calibration or reference for upscaling to area-wide approaches based on optical satellite imagery.

Against this background, the current work employs satelliteand UAV-based remote sensing, machine learning and knowledge-based image understanding as well as spatial/ecological modelling techniques to acquire detailed information on the presence and state of Tillandsia spp. in the study area (Tarapacá region) and to model its geo-ecological niche.

\section{STUDY AREA}

The study area is part of the Atacama Desert in the Tarapacá region, northern Chile. It extends for a $90 * 30 \mathrm{~km}$ coastal stripe at approx. $20^{\circ} \mathrm{S}$ (Figure 1). The area is characterized by hyperarid conditions which are a result of the effects of the stable high-pressure system of the western Pacific Ocean, the drying effect of the Humboldt current, and the rain shadow effect of the Andes impeding the penetration of moisture by the eastern trade winds.

\section{METHODS}

The general approach subdivides into the following four work steps:

(1) UAV-based mapping of vegetation cover.

(2) Delineation of Tillandsia fields using a two-step sequence of supervised spatiospectral classification and rule-based postprocessing.

(3) Fractional Vegetation Cover (FVC): regression analysis using area-wide predictors based on WorldView-3 and the SRTM-30 model.

(4) Analysing the topographic controls and bioclimatic envelope of Tillandsia spp.

\subsection{UAV-based generation of vegetation cover}

Unmanned Aerial Vehicles (UAVs) can be used to generate training, validation and testing data for statistical model generation based on area-wide satellite-based spatial-spectral predictors and further environmental or topographic variables. Compared to point- or plot-based information obtained by ground trothing in the field, UAV-based reference data collection can provide advantages in terms of data quantity,

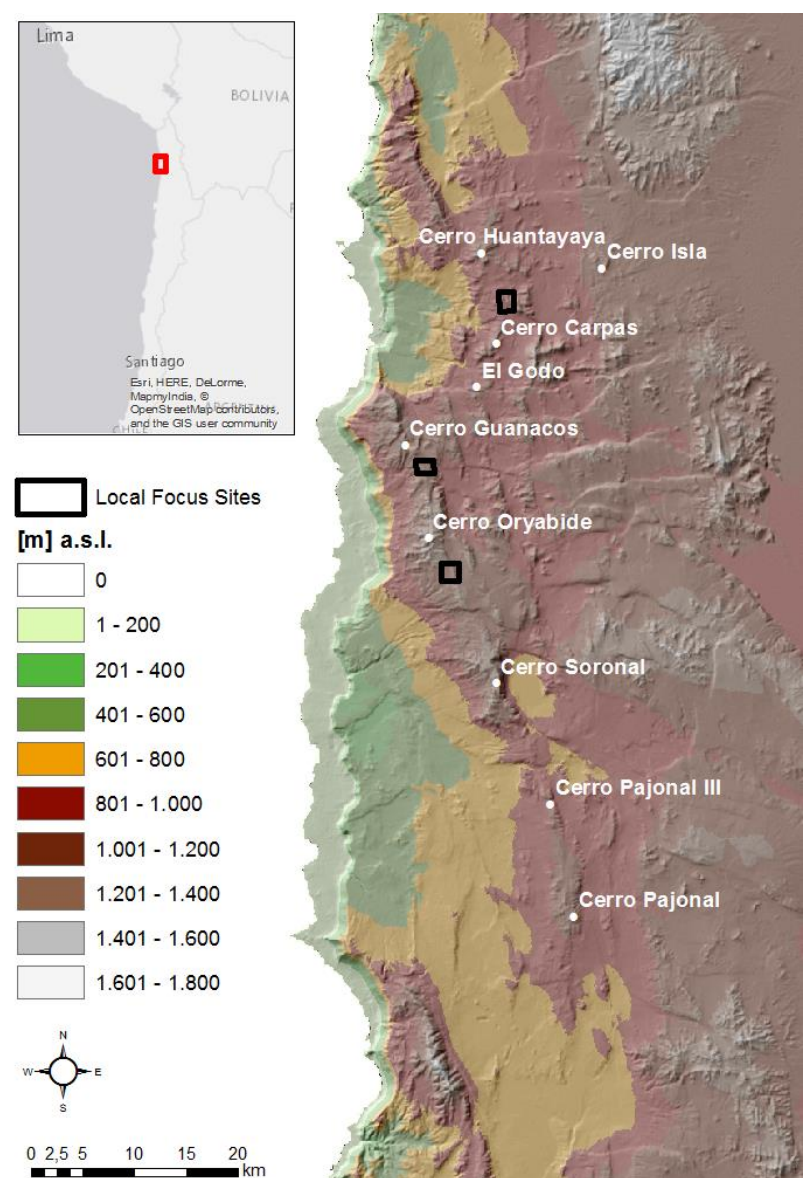

Figure 1. Study area in the coastal Atacama Desert, Chile. The hills ("Cerro") serve as landmarks for orientation and demarcate locations where nearby Tillandsia fields have been reported in the literature (Pinto et al., 2006).

spatial coverage and representativeness. Moreover, it allows the consideration of otherwise rather inaccessible regions and can advantageous in terms of operational costs.

Three local focus sites (cp. Figure 1) within the study area have been chosen for the acquisition of subdecimeter information on vegetation cover to be used later as training and testing data for coarser but area-wide calculation of FVC. The choice of the local focus areas was guided by the intention to represent different vegetation densities and patterns formations. Tillandsia spp. are known to form banded patterns as a result of self-organizing processes to maximize fog water deposition Depending on the topographic conditions or population fitness, they also form reticulate or clustered patterns (Hesse 2012).

During several flight campaigns in 2014 and 2015, approximately 3000 to 4000 RGB-images have been captured per site using a consumer digital SLR camera mounted on the parachute-UAV "SUSI-62" (Thamm 2011). The images have been processed using a Structure-from-Motion approach (Mancini et al., 2013) as implemented in the Photoscan Pro software to generate $3 \mathrm{~cm}$ RGB orthomosaics and $6 \mathrm{~cm}$ digital surface models (Figure 2). 


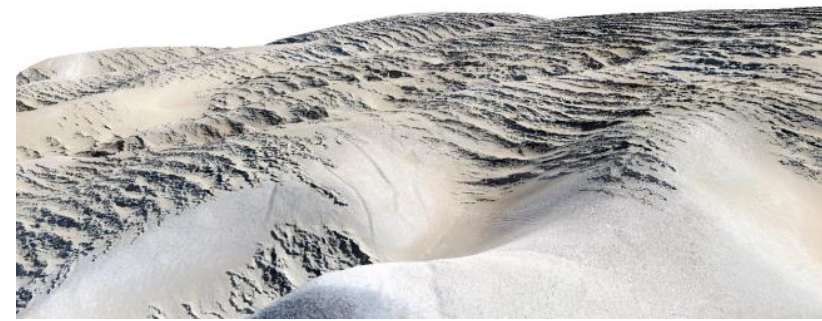

Figure 2. Subset of the digital surface model of the "Oryabide" local focus site with draped $3 \mathrm{~cm}$-resolution orthomosaics.

For the extraction of Tillandsia vegetation cover, a Geographic Object-based Image Analysis Approach (GEOBIA) has been developed, resulting in maps with high agreement comparing to the reference of manual photointerpretation (Kappa Index of Agreement $\kappa=0.99 ; \mathrm{n}=400$; simple random sampling, focus site "Oryabide"). Minor discrepancies may occur in areas with very sparse or isolated, often diminishing vegetation patches.

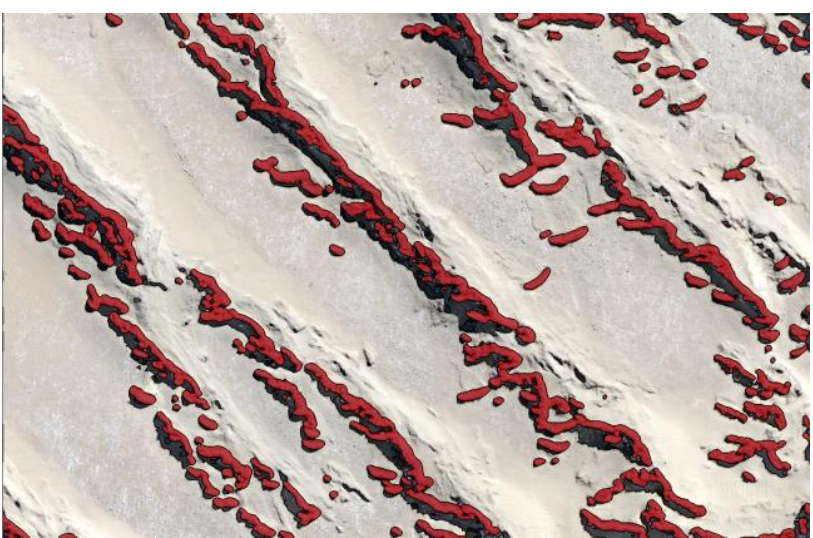

Figure 3. Example of the vegetation cover information extracted using knowledge-based image analysis.

\subsection{Delineation of Tillandsia fields}

This processing step has been implemented to obtain a coarse delineation of Tillandsia fields within the study area, with the aim to constrain the subsequent calculation of VCF to a minimal candidate region. This allows the induction of more specific, accurate prediction models and impedes false positives.

Due to spare vegetation coverage and limited photosynthetic activity, neither spectral vegetation indices nor complex models induced in multispectral feature spaces allow an accurate discrimination of Tillandsia vegetation. Instead, we suggest the use of multiscale spatial features to complement the spectral feature space. A set of 280 spatial and spectral features has been derived from 8-band multispectral and panchromatic WorldView-3 surface reflectance data using multiscale image segmentation and object-based feature extraction. The feature set includes per-object spectral and vegetation indices means, standard deviations, minimum pixel values, contextual, textural and shape information, extracted from stepwise incremented segmentation scales. For more detailed information the reader is referred to (Benz et al., 2004; Wolf 2013; Trimble 2014).

Using Recursive Feature Elimination based on the Random Forest algorithm (Breiman 2001; Kuhn 2016), the extensive feature set has been incrementally reduced discarding the weakest features with the aim to reduce the data volume and computational cost. Graphing the number of variables against cross-validated Kappa values (Figure 4) defined the optimal feature subset with a dimensionality of 17 .

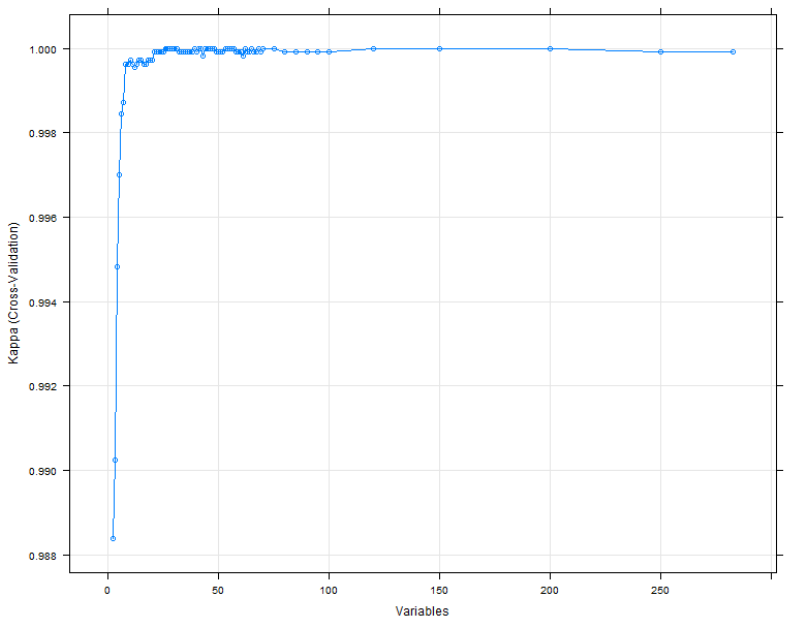

Figure 4. Plotting model performance against incrementally reduced data dimensionality to determine optimal feature subsets.

Training regions representing Tillandsia vegetation have been manually selected from the pansharpened WorldView-3 image. Using three repeats of 10 -fold cross-validation, prediction models implemented in the caret-package (Kuhn 2016) of the $\mathrm{R}$ Statistical Computing framework have been trained and tuned on the basis of the feature subset (Table 1). The best performing model was selected based on Kappa Index of Agreement $\kappa$ (Cohen 1960).

\begin{tabular}{|c|c|c|c|}
\hline Model & method & Packages & $\begin{array}{l}\text { Tuning } \\
\text { Parameters }\end{array}$ \\
\hline CART & rpart & rpart & $c p$ \\
\hline Bagged CART & treebag & $\begin{array}{l}\text { ipred, } \\
\text { plyr, } \\
\text { e1071 }\end{array}$ & None \\
\hline SVM rbf & svmRadial & kernlab & sigma, $C$ \\
\hline $\begin{array}{l}\text { Random } \\
\text { Forest }\end{array}$ & $\mathrm{rf}$ & $\begin{array}{l}\text { randomfor } \\
\text { est }\end{array}$ & mtry \\
\hline $\begin{array}{l}\text { Stoch. Grad. } \\
\text { Boosting }\end{array}$ & $\mathrm{gbm}$ & gbm, plyr & $\begin{array}{l}\text { n.trees, } \\
\text { interact..depth, } \\
\text { shrink., n.minobs. }\end{array}$ \\
\hline $\begin{array}{l}\text { Partial Least } \\
\text { Squares }\end{array}$ & kernelpls & pls & ncomp \\
\hline Naive Bayes & $\mathrm{nb}$ & klaR & $\begin{array}{l}f L, \text { usekernel, } \\
\text { adjust }\end{array}$ \\
\hline $\begin{array}{l}\text { k-Nearest } \\
\text { Neighbors }\end{array}$ & knn & & $k$ \\
\hline
\end{tabular}

Table 1. Models available via the caret package.

Simple postprocessing filters and decision rules have been implemented in eCognition software to generalize the vegetation mask to contiguous Tillandsia field polygons. 


\subsection{Upscaling vegetation cover to Vegetation Cover Fraction (VCF)}

Vegetation cover as derived from UAV-imagery (cp. Section 3.1) was aggregated to a $30 \mathrm{~m} \times 30 \mathrm{~m}$ grid, defining the response of VCF for fitting a regression model based on Random Forests, leaving the default parameters of the $\mathrm{R}$ randomForest-package implementation (Liaw 2015). Equally aggregated to the analysis grid, a set of predictors has been derived from WorldView-3 and SRTM-30 (Table 1). An appropriate co-registration of UAV-based response variable (vegetation cover) and predictor variables has been achieved by automated tie-point generation and locally optimized correction of the UAV orthoimages.

\begin{tabular}{ll}
\hline Variable & Alias \\
\hline Mean MS band 1 & Mean.B1 \\
Mean MS band 2 & Mean.B2 \\
Mean MS band 3 & Mean.B3 \\
Mean MS band 4 & Mean.B4 \\
Mean MS band 5 & Mean.B5 \\
Mean MS band 6 & Mean.B6 \\
Mean MS band 7 & Mean.B7 \\
Mean MS band 8 & Mean.B8 \\
Mean NDVI "(B7-B5)/(B7+B5)" & NDVI \\
MEAN NDRI "(B6-B5)/(B6+B5)" & NDRI \\
Mean variance filter PAN (kernel size = 5) & Mean.SD5 \\
Mean variance filter PAN (kernel size $=\mathbf{1 5})$ & Mean.SD15 \\
SRTM-30 Slope & Mean.SLOPE \\
SRTM-30 Aspect & Mean.ASPECT \\
\hline
\end{tabular}

Table 2. Predictor variables for the area-wide estimation of Vegetation Cover Fraction (VCF).

\section{RESULTS}

Figure 5 shows the optimized feature subset with 17 out of 280 dimensions with the according permutation-based variable importance scores. The prefixed denotes the segmentation scale. For example the prefix "X320" refers to a feature extracted from a segmentation level with scale 320 (Baatz, Schäpe, 2000); "X0" refers to the pixel level. The best performing model (cp. Table 1) was induced using the Random Forest algorithm, with $\kappa=0.975$ (non-random / biased sampling).

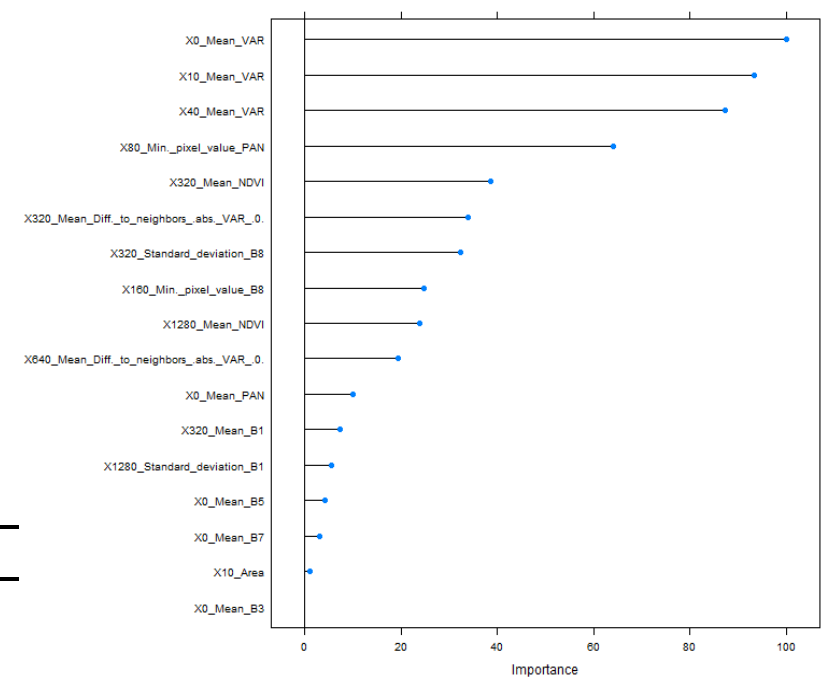

Figure 5. Permutation-based variable importance of Random Forest model (scaled to the range 0 to 100 ).

VCF could be derived using Random Forest regression (no. of trees $=1000$, mtry $=4$ ) with a mean of squared residuals of 0.000198 indicates the contribution of individual input variables, showing the particular importance of the spatial variance filter (kernel size $15 \mathrm{px}$ ) using the panchromatic WorldView-3 band (Figure 6).

Topographic constraints can be described at a $30 \mathrm{~m}$ x $30 \mathrm{~m}$ analysis grid using the delineated Tillandsia fields and SRTM30-based elevation, slope and aspect. Moreover, the distance of Tillandsia fields to the coastline has been calculated. The Tillandsia fields distribute in a range between $810 \mathrm{~m}$ and 1280 $\mathrm{m}$ a.s.l. which differs from a $930 \mathrm{~m}$ to $1050 \mathrm{~m}$ range reported in the literature (Rundel et al., 1997). The calculated average slope, facing predominantly southwest, is $8^{\circ}$.

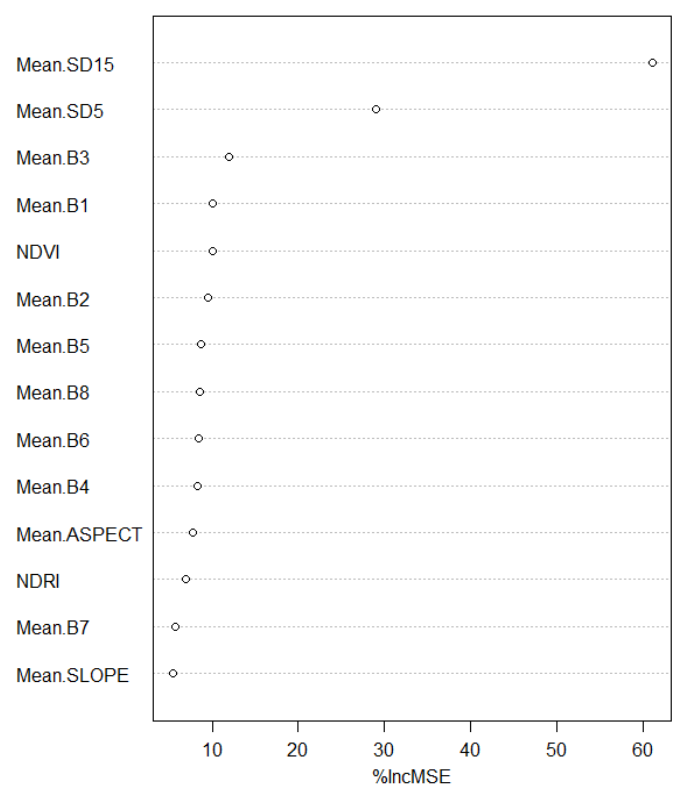

Figure 6. Contribution of individual variables to the Vegetation Cover Fraction (VCF) model. 


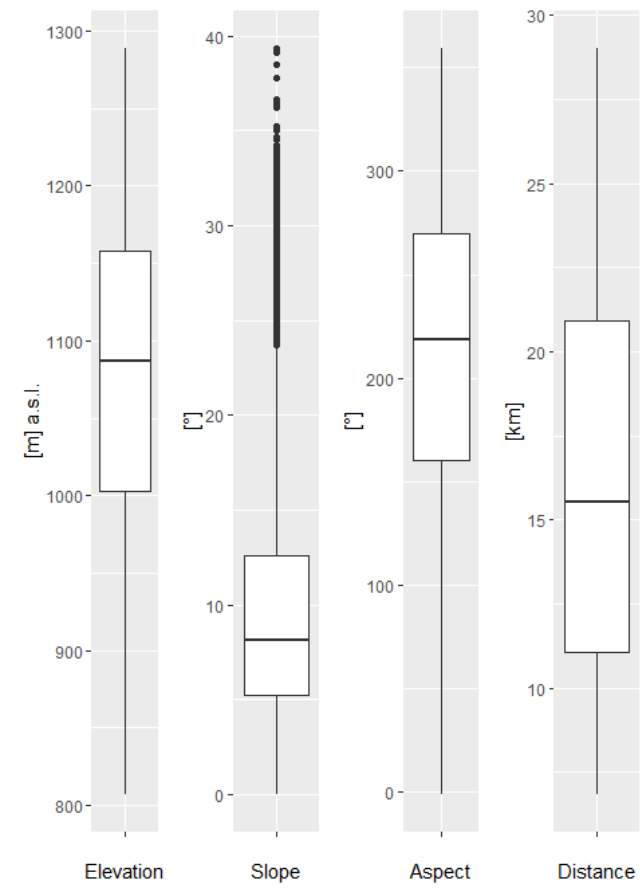

Figure 7. Topographic constraints of Tillandsia spp.

\section{SUMMARY AND OUTLOOK}

This contribution has demonstrated the application of remote sensing, machine learning and spatial pattern/GIS analysis techniques to acquire detailed information on the spatial distribution of Tillandsia spp. in the Tarapacá region as a base to better understand its bioclimatic and topographic envelope. Spatial and spectral predictors extracted from WorldView-3 satellite data have been used to map present Tillandsia vegetation in the study area. Regression models on Vegetation Cover Fraction (VCF) have been generated using satellite-based and topographic variables while using aggregated high spatial resolution information on vegetation cover derived from UAV flight campaigns as a reference for model training. The results provided a first step towards mapping and modelling the topographic as well as bioclimatic factors determining the spatial distribution patterns of the threatened and endemic Tillandsia fog oases in the Atacama, Chile.

\section{ACKNOWLEDGEMENTS}

We sincerely thank the DigitalGlobe Foundation for supporting this research by providing the WorldView-3 satellite data.

\section{REFERENCES}

Baatz M., Schäpe A., 2000. Multiresolution Segmentation: an optimization approach for high quality multi-scale image segmentation; In: J. Strobl, T. Blaschke, G. Griesebner (eds): Angewandte geographische Informationsverarbeitung XII: Beiträge zum AGIT-Symposium Salzburg 2000. Heidelberg: Wichmann Verlag; 12-23.

Benz U. C., Hofmann P., Willhauck G., Lingenfelder I., Heynen M., 2004. Multi-resolution, object-oriented fuzzy analysis of remote sensing data for GIS-ready information. ISPRS Journal of Photogrammetry and Remote Sensing, 58, 3-4, 239-258.

Borthagaray A. I., Fuentes M. A., Marquet P. A., 2010. Vegetation pattern formation in a fog-dependent ecosystem. Journal of Theoretical Biology, 265, 1, 18-26.

Breiman L., 2001. Random Forests. Machine Learning, 45, 1, 5-32.

Cereceda P., Osses P., Larrain H., Farias M., Lagos M., Pinto R., Schemenauer R., 2002. Advective, orographic and radiation fog in the Tarapacá region, Chile. Atmospheric Research, 64, 1$4,261-271$

Cohen J., 1960. A Coefficient of Agreement for Nominal Scales. Educational and Psychological Measurement, 20, 1, $37-46$.

Hesse R., 2012. Spatial distribution of and topographic controls on Tillandsia fog vegetation in coastal southern Peru: Remote sensing and modelling. Journal of Arid Environments, 78, 3340.

Kuhn M., 2016. Package 'caret'. https://cran.rproject.org/web/packages/caret/caret.pdf.

Latorre C., González A. L., Quade J., Fariña J. M., Pinto R., Marquet P. A., 2011. Establishment and formation of fogdependent Tillandsia landbeckii dunes in the Atacama Desert: Evidence from radiocarbon and stable isotopes. Journal of Geophysical Research, 116, G3.

Liaw A., 2015. Breiman and Cutler's Random Forests for Classification and Regression. https://cran.rproject.org/web/packages/randomForest/randomForest.pdf.

Mancini F., Dubbini M., Gattelli M., Stecchi F., Fabbri S., Gabbianelli G., 2013. Using Unmanned Aerial Vehicles (UAV) for High-Resolution Reconstruction of Topography: The Structure from Motion Approach on Coastal Environments. Remote Sensing, 5, 12, 6880-6898.

Pinto R., Barria I., Marquet P. A., 2006. Geographical distribution of Tillandsia lomas in the Atacama Desert, northern Chile. Journal of Arid Environments, 65, 543-552.

Rundel P. W., Palma B., Dillon M. O., Sharifi M. R., Boonpragob K., 1997. Tillandsia landbeckii in the coastal Atacama Desert of northern Chile. Remote Sensing, 70, 341349.

Rutllant J. A., 2003. Climate dynamics along the arid northern coast of Chile: The 1997-1998 Dinámica del Clima de la Región de Antofagasta (DICLIMA) experiment. Journal of Geophysical Research, 108, D17.

Schulz N., 2009. Loma-Formationen der KüstenAtacama/Nordchile unter besonderer Berücksichtigung rezenter Vegetations- und Klimaveränderungen: $\mathrm{PhD}$ Dissertation. Geographical Institute, Erlangen-Nürnberg University. 
Schulz N., Aceituno P., Richter M., 2011. Phytogeographic divisions, climate change and plant dieback along the coastal desert of northern Chile. Erdkunde, 65, 2, 169-187.

Schulz N., Boisier J. P., Aceituno P., 2012. Climate change along the arid coast of northern Chile. International Journal of Climatology, 32, 12, 1803-1814.

Thamm H. P., 2011. SUSI 62 A ROBUST AND SAFE PARACHUTE UAV WITH LONG FLIGHT TIME AND GOOD PAYLOAD. In: UAV-g 2011, Conference on Unmanned Aerial Vehicle in Geomatics, Zurich, Switzerland; XXXVIII-1/C22.

Trimble, 2014. eCognition Developer 9.0 Reference Book.

Westbeld A., Klemm O., Grießbaum F., Sträter E., Larrain H., Osses P., Cereceda P., 2009. Fog deposition to a Tillandsia carpet in the Atacama Desert. Annales Geophysicae, 27, 9, 3571-3576.

Wolf N., 2013. Object Features for Pixel-based Classification of Urban Areas Comparing Different Machine Learning Algorithms. Photogrammetrie - Fernerkundung Geoinformation, 2013, 3, 149-161. 